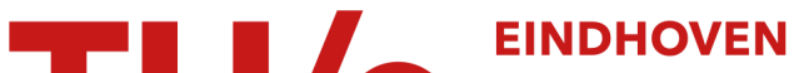 UNIVERSITY OF TECHNOLOGY
}

\section{On the use of planar EBGs in one dimensional (1D) scanning printed arrays}

\section{Citation for published version (APA):}

Llombart, N., Neto, A., Gerini, G., \& de Maagt, P. J. I. (2005). On the use of planar EBGs in one dimensional (1D) scanning printed arrays. In Proceedings of the European Radar Conference, 2005, EURAD 2005, 6/7 October 2005, Paris, France (pp. 303-306). Institute of Electrical and Electronics Engineers. https://doi.org/10.1109/EURAD.2005.1605624

DOI:

10.1109/EURAD.2005.1605624

Document status and date:

Published: 01/01/2005

\section{Document Version:}

Publisher's PDF, also known as Version of Record (includes final page, issue and volume numbers)

\section{Please check the document version of this publication:}

- A submitted manuscript is the version of the article upon submission and before peer-review. There can be important differences between the submitted version and the official published version of record. People interested in the research are advised to contact the author for the final version of the publication, or visit the $\mathrm{DOI}$ to the publisher's website.

- The final author version and the galley proof are versions of the publication after peer review.

- The final published version features the final layout of the paper including the volume, issue and page numbers.

Link to publication

\section{General rights}

Copyright and moral rights for the publications made accessible in the public portal are retained by the authors and/or other copyright owners and it is a condition of accessing publications that users recognise and abide by the legal requirements associated with these rights.

- Users may download and print one copy of any publication from the public portal for the purpose of private study or research.

- You may not further distribute the material or use it for any profit-making activity or commercial gain

- You may freely distribute the URL identifying the publication in the public portal.

If the publication is distributed under the terms of Article 25fa of the Dutch Copyright Act, indicated by the "Taverne" license above, please follow below link for the End User Agreement:

www.tue.nl/taverne

Take down policy

If you believe that this document breaches copyright please contact us at:

openaccess@tue.nl

providing details and we will investigate your claim. 


\title{
On the Use of Planar EBGs in One Dimensional (1D) Scanning Printed Arrays
}

\author{
N. Llombart ${ }^{1}$, A. Neto ${ }^{1}$, G. Gerini ${ }^{1}$, P. De Maagt ${ }^{2}$ \\ ${ }^{1}$ TNO Defense, Security and Safety, TNO, Den Haag 2597 AK, The Netherlands \\ E-Mail: nuria.llombartjuan, andrea.neto, giampiero.gerini@tno.nl \\ 2 Electromagnetics Division, European Space Agency, 2200 AG, Noordwijk, The Netherlands \\ E-mail: Peter.de.Maagt@esa.int
}

\begin{abstract}
In a companion paper [1] presented in this same conference, the use of Planar Circularly Symmetric (PCS) Electromagnetic Band-Gap (EBG) structures for optimizing the performances of single antenna elements is discussed. A completely planar antenna with $20 \%$ of bandwidth which does not suffer from surface wave effects is presented. The key advantage of using this sort of super structures is that they are planar and thus very cheap to manufacture with respect to alternative EBG structures based on vertical pins [2] [3]. In this contribution the design efforts are aimed at using planar EBGs to enhance the performances of 1D scanning arrays. This kind of arrays, are becoming increasingly more requested for airborne SAR type of instruments and lower cost naval radars. The purpose of this paper is to provide a step toward the feasibility of fullyintegrated planar arrays at very low costs providing a conceptual design. In particular, a design characterized by relatively large bandwidths $(\mathbf{B W} \approx 15 \%)$, can be achieved when the arrays are scanned up to $40^{\circ}$ in one dimension only. This design will lead to the manufacture of a phased array demonstrator which do not suffer from surface waves.
\end{abstract}

\section{INTRODUCTION}

The development of low profile Synthetic Aperture Radar (SAR) front ends is the subject of several recent investigations. In most SAR systems the chosen solution is $1 \mathrm{D}$ or mostly $1 \mathrm{D}$ scanning arrays [4], [5]. The reason for this is on one side the fact that the beam width requirements on the two orthogonal planes are significantly different and on the other side that a hybrid mechanical-electronic steering can be a much cheaper solution than a purely electronically steered 2D scanning array. Especially considering that in many situations a slow beam scanning in the wider beam plane is sufficient. Typical requirements for S.A.R. applications involve bandwidth (BW) larger than $10 \%$ and scanning until 45 degrees in the longitudinal plane.

Different trade offs can lead to the preference of a technological solution with respect to another. The overall cost is certainly an important parameter. In this paper we present a design procedure for low cost and low profile front ends to be used in SAR systems. The strategy is based on the fact that the Transmit/Receive (T/R) modules are integrated on the same chips that contain the antenna array elements. These latter elements are resonant dipoles printed on the opposite side of the metallic plane that constitutes the ground for the micro-strip feeding lines and the T/R modules. The electromagnetic coupling between the two half spaces defined by the ground plane is achieved via resonant slots. The antenna and the T/R modules can be made completely planar. There are in particular two significant advantages in using completely planar technology. The first is that it renders it inexpensive

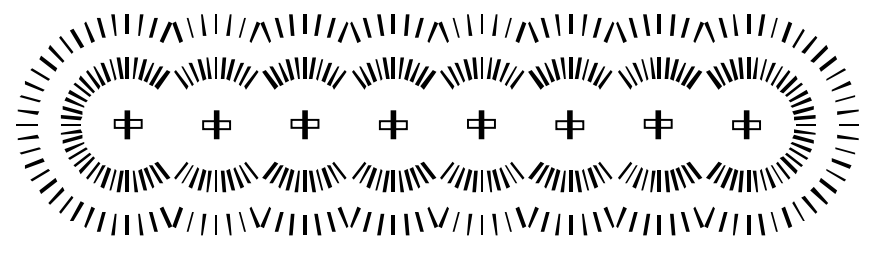

Fig. 1. 1D scanning array composed of 8 elements with PCS-EBGs.

since the manufacturing steps are reduced with respect to other designs that require cavity backing or vertical metallic connections to transfer the signal vertically from the lower feeding planes to the antennas. The second is that spurious radiation from the vertical connections would seriously affect the level of cross polarization as explained in [5] and [6].

Focusing the attention on these purely planar structures, a useful approach is to use dense dielectric slabs in order to maximize the front to back ratio. Alternative solutions using non dense dielectrics in the radiating half spaces [7] (and there cited references) necessitate the introduction of a backing reflector that supports parallel plate waveguide modes. This shifts the design difficulties from the antenna layer to the feeding layer. Nevertheless the dense and thick dielectric layers tend to excite and support surface wave propagation whose control is now the key design difficulty.

If one limits its attention to 1D scanning arrays, the advantages associated to the planarity of the structure are achieved without sacrificing the performances due to surface wave losses thanks to the use of planar circularly symmetric Electromagnetic Band Gap substrates (PCS-EBG). An example of one such planar array with PCS-EBG is shown in fig. 1. In fact PCS-EBGs are used in this work to reduce the power launched in surface wave by each one of the antennas composing the array.

\section{Design of 1D ARRAYS BASED ON PCS-EBGS}

The present PCS-EBG concept is very well suited for 1D scanning arrays. The key design attention is to use linearly polarized antenna elements arrayed in such a way that their interaction via surface wave is reduced. A slot coupled dipole launches TM waves that are dominant on the E-plane cut of the slab, and have an angular distribution of the field intensity $\sin \phi$, see fig. 2. For this reason one can use PCS-EBGs radially oriented, as in fig. 3, to reduce the TM waves in an angular sector, $\phi \in\left[\alpha, 180^{\circ}-\alpha\right] \cup\left[-180^{\circ}+\alpha,-\alpha\right]$. The array period in the H-plane can then be diminished with respect 


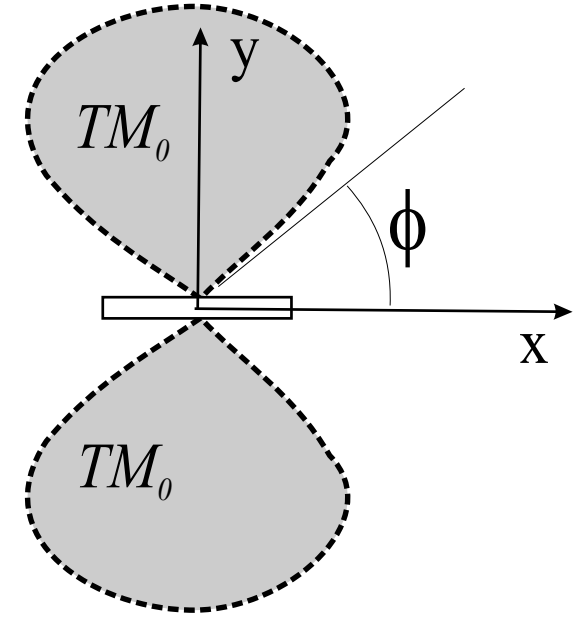

Fig. 2. $\phi$ distribution of the TM field radiated by the selected antenna.

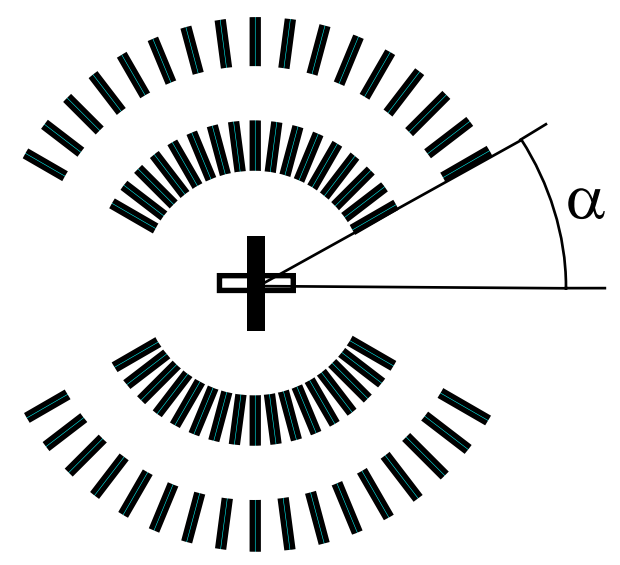

Fig. 3. Reduced EBG configuration that allows to control $73 \%$ of the power.

to the cases when full rings were employed, ensuring better scanning performances in this H-plane.

A first example is shown in the inset of fig. 4 where a two element array is depicted. The design of the EBG is performed as in [1]. The parameters defining the EBG are the same that the ones of the companion paper, but they are scaled to operate at X-band (10-12Ghz): $\rho_{1}=9 \mathrm{~mm}, d=6.85 \mathrm{~mm}, l_{g}=$ $3.3 \mathrm{~mm}$. The PCS-EBG is present now only in a sector as in 3 , where $\alpha=52^{\circ}$. Thanks to the sector configuration, we can place the elements at a distance of $14 \mathrm{~mm}$, that corresponds to a maximum scanning without grating lobes of $51.8^{\circ}$ at $12 \mathrm{GHz}$.

The comparisons between the S-parameters obtained using two isolated antennas or using two EBG surrounded antennas, fig. 4, are shown in fig 5. In the EBG case, the $S_{11}$ is lower than $-10 d B^{\prime} s$ over a larger BW (in the order of $20 \%$ ). This is encouraging especially in view of the fact that this is not only impedance BW but radiation BW, i.e. the efficiency of this small antenna array is also very high, while the one in absence of the EBG is relatively low. To highlight this aspect the radiation patterns of the array with and without EBG's have been calculated. The gain in $\mathrm{dB}$ is compared in the two configurations, fig. 6 . The increase in gain from 5 to $10 \mathrm{dBs}$ is proof of the increase of efficiency (no power is lost in surface

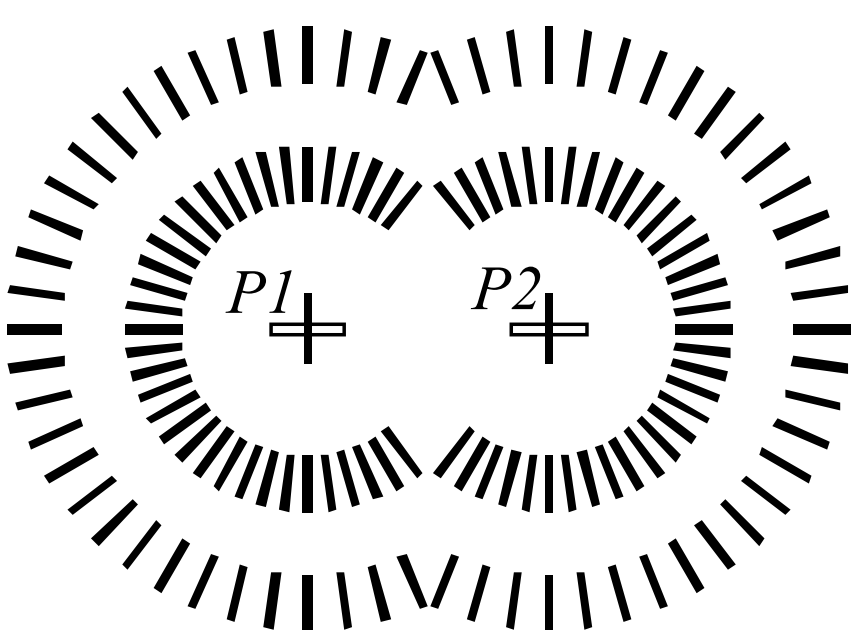

Fig. 4. Geometry of two printed antennas surrounded by a PCS-EBG. Each of the rings is not closed to allow reduced spacing between the array elements. The spacing is $14 \mathrm{~mm}$.

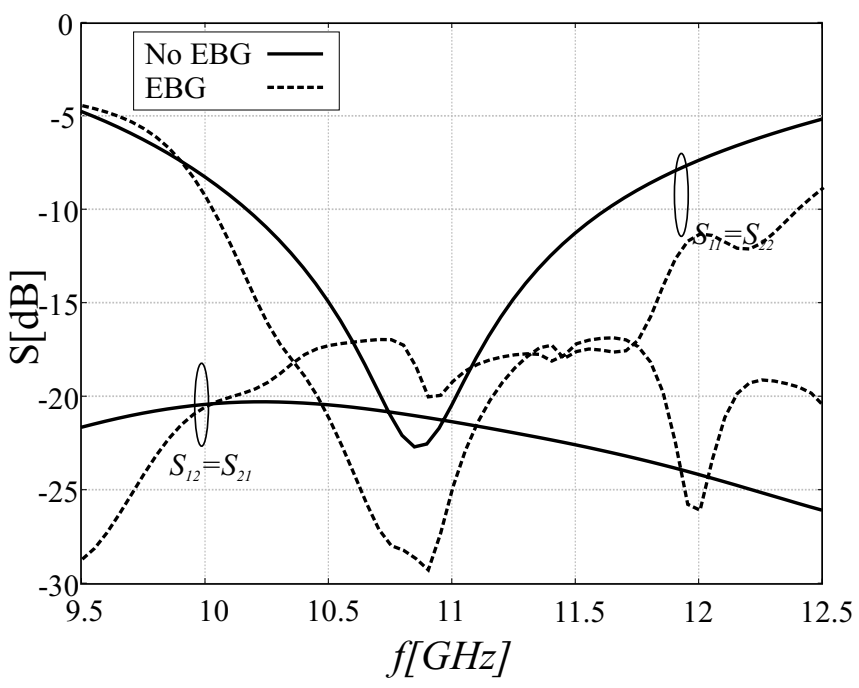

Fig. 5. S-parameters for the configurations in fig. 4.

waves) and of the larger effective area, both due to the presence of the EBGs.

When the attention is focused on the mutual coupling between the two antennas, one can observe that it is higher in the case in which the PCS-EBGs are used. The reason why the inclusion of the EBGs increases the mutual coupling is that a small portion of power is coupled from the first antenna to the second via reflected surface waves. In fact the portion of surface wave power that is radiated in the angular regions shown is fig. 3 and thus controlled by the EBGs is $73 \%$. The rest $27 \%$ of the power is unaccounted for. For the geometry of the two elements array of fig.4, the power launched by each antenna and not accounted for by the EBG is about $13 \%$ of the total power launched in surface waves. This latter can actually contribute to the interaction with nearby elements.

\section{REDUCTION OF SCAN BLINDNESS IN 1D ARRAYS}

Despite the fact that there is some coupling between two subsequent elements arrayed in the H-plane, such coupling does not disturb significantly since it not induces scan blindness problems. In fact scan blindness occurs when the mutual coupling between elements occurs by means of waves 


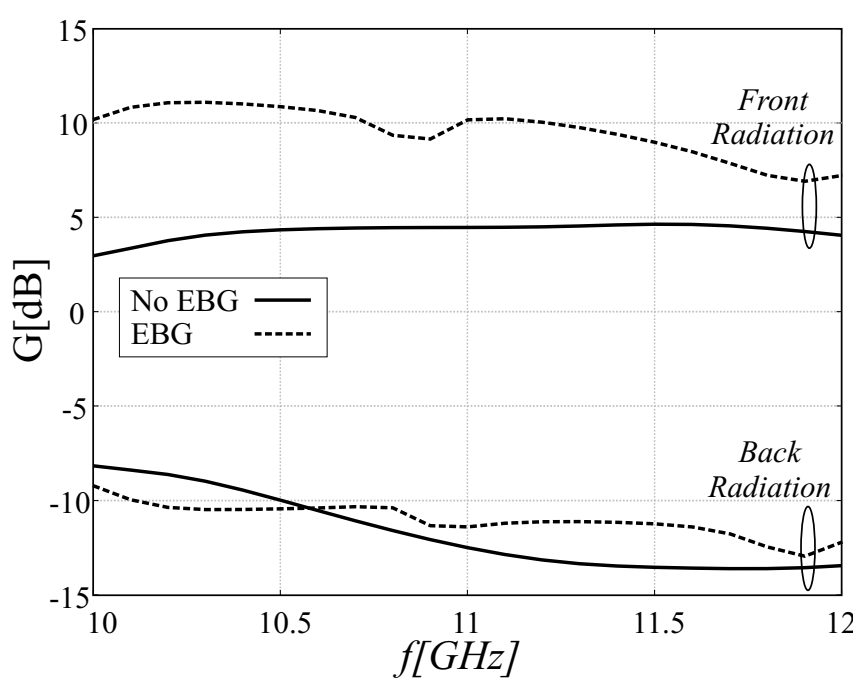

Fig. 6. Gain in front or back radiation for the twin antenna configurations in fig. 4.

propagating with propagation constants that are equal to the propagation constants of a Floquet Wave $(\mathrm{FW})$. For the case in which the H-plane corresponds to the $\mathbf{i}_{x}-\mathbf{i}_{z}$, the relevant FWs are $k_{x m}=k_{0} \sin \theta+\frac{2 \pi m}{d_{x}}$. In fig. 7, the spectral plane $k_{x}, k_{y}$ is drawn. Let us define $k_{\rho}=\sqrt{k_{x}^{2}+k_{y}^{2}}$. The circles pertinent to $k_{\rho}=k_{s w}$, where $k_{s w}$ is the propagation constant of the dominant $T M_{0}$ wave, and to $k_{\rho}=k_{0}$, with $k_{0}$ the free space propagation constant are both plotted. On the $k_{x}$ axis, the FWs of lower indices $\left(m_{x}=-1, m_{x}=0, m_{x}=1\right)$ are drawn with continuous circles for broad side beams. Dashed circles instead represent the location of the corresponding FW when the beam is scanning to the maximum pointing angle, $\theta_{\max }$. All the FWs move, maintaining the distances between them, as the array beam is scanned and this movement is represented by the arrows.

If the slots were oriented along $\mathbf{i}_{y}$ and the array was scanned toward positive angles, all the FW shift to the right in fig. 7. The scan blindness would occur as soon as the FW of index -1 would intercept the $k_{\rho}=k_{s w}$ circle. This could occur for relatively narrow scanning angles. The surface propagation constant is $k_{s w}=1.49 k_{0}$ in the present substrate and the periodicity $d_{x}=14 \mathrm{~mm}=0.56 \lambda_{0}$, both at $12 \mathrm{GHz}$. This configuration which will lead to a scan blindness when $\theta=17.2^{\circ}$.

In the present design, however, the slots are oriented along $\mathbf{i}_{x}$. The slots do not radiate waves in the direction $k_{x}=0$ $(\phi=0)$. Thus the only surface wave contributing to the mutual coupling between different slots in the array are those reflected at the intersection between two EBG circles. Let us assume that $\alpha$ is the angle that the direct and reflected waves form with the $\mathrm{x}$-axis, see fig. 3 . The corresponding projection into the $k_{x}$ axis is $k_{s w} \cos \alpha$. Since this projection is necessarily smaller than $k_{s w}$, the angle at which scan blindness could occur is greatly reduced in this situation. The location of this scanning direction is represented in the $k_{x}, k_{y}$ by the crosses on the $k_{x}$ axis. In the present case, $\alpha=52^{\circ}$, then the scan blindness effect is reduced to $\theta=60.3^{\circ}$, outside the scanning without grating lobes region, $\theta=51.8^{\circ}$.

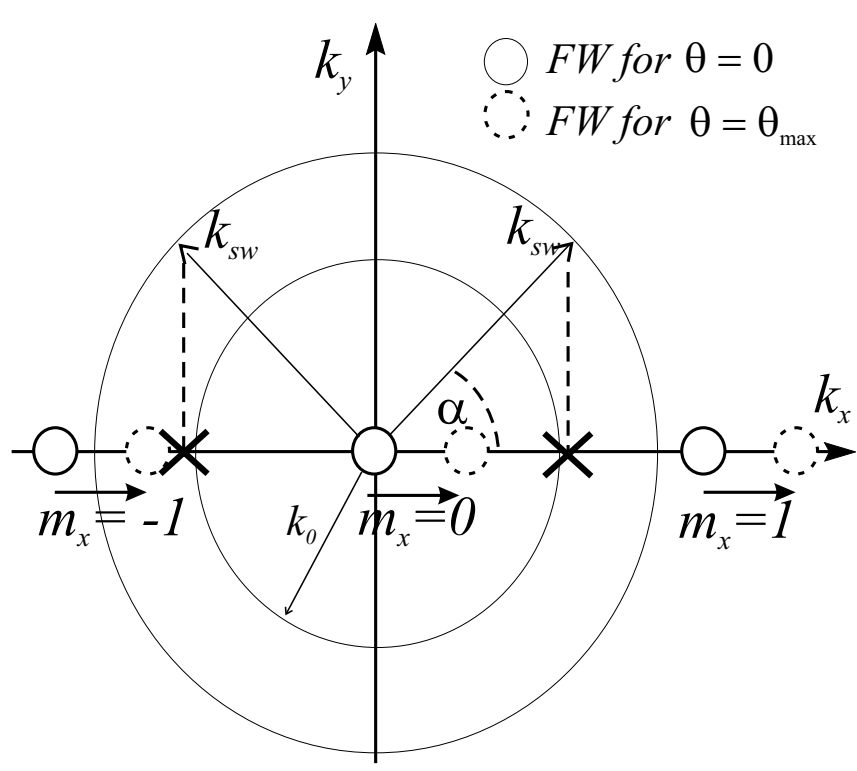

Fig. 7. Spectral plane and FW displacement as a function of the scanning angle.

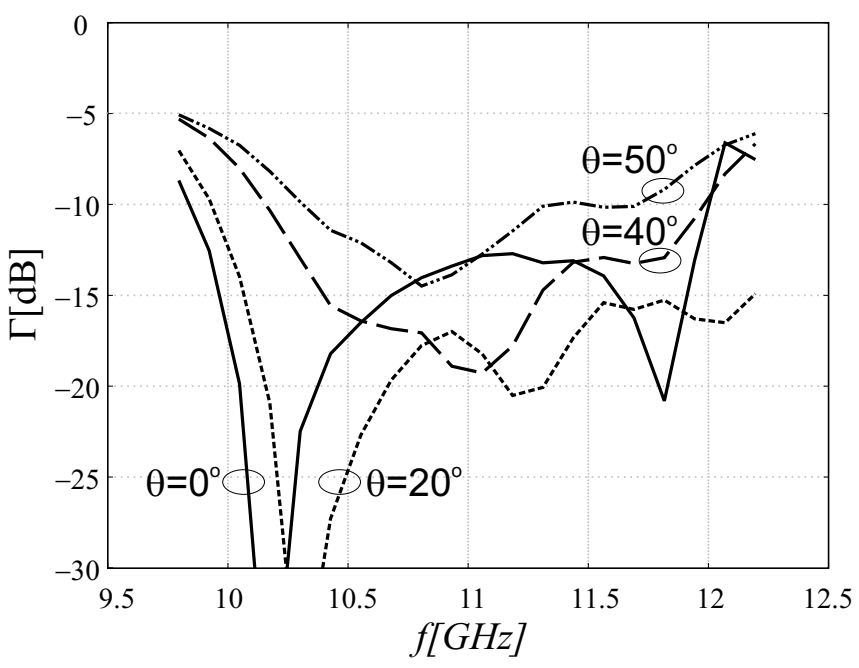

Fig. 8. Measured and calculated Reflection coefficient of the complete array for different scanning angles.

\section{1D SCANNING ARRAY PROTOType}

In this section, an $\mathrm{X}$ band demonstrator based on the design indications of section II are described. The prototype aims to demonstrate the potentials of PCS-EBG technology to realize pure $1 \mathrm{D}$ electronic beam scanning.

The 1D scanning array is composed of eight slot coupled dipoles arrayed in the $\mathrm{H}$ plane as in fig. 1. The array is printed on dielectric material with $\epsilon_{r}=9.8$ commercially available from Rogers. The distance between the elements is $14 \mathrm{~mm}$ which guarantees a grating lobes free scanning until $52^{\circ}$, at the upper frequency of $12 \mathrm{GHz}$. All antennas are fed via $50 \Omega$ micro-strip lines connected to coaxial cables after equivalent electric paths. The array has been simulated with Ansoft Designer. The reflection coefficient for the complete array is shown in fig. 8. The input impedance bandwidth is more than $20 \%$ for broad side scanning, more than $15 \%$ for beams pointing at $40^{\circ}$ and more than $10 \%$ for beams pointing at $50^{\circ}$. 


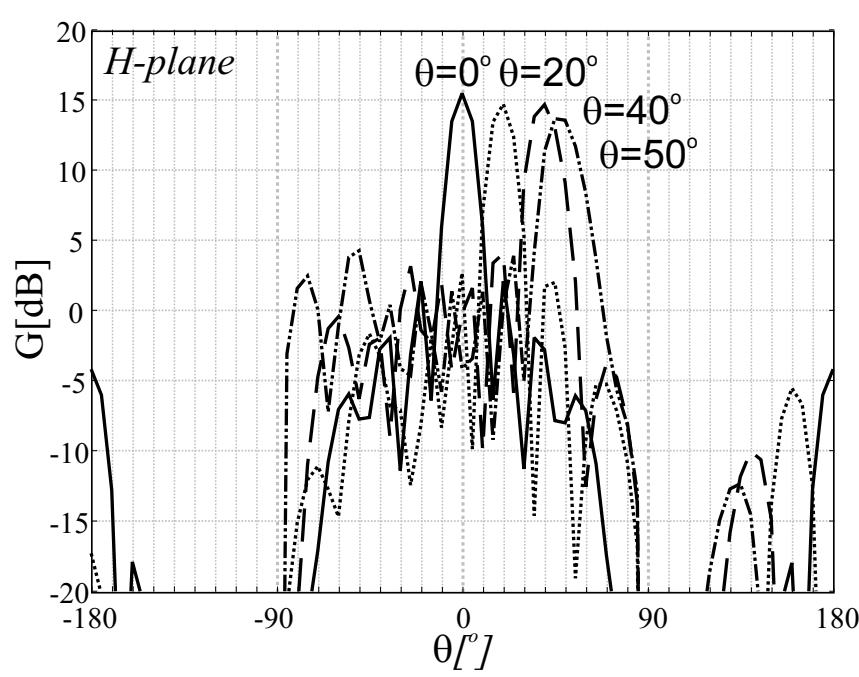

Fig. 9. Co-polar radiation patterns for different scanning angles in the $\mathrm{H}$ plane.

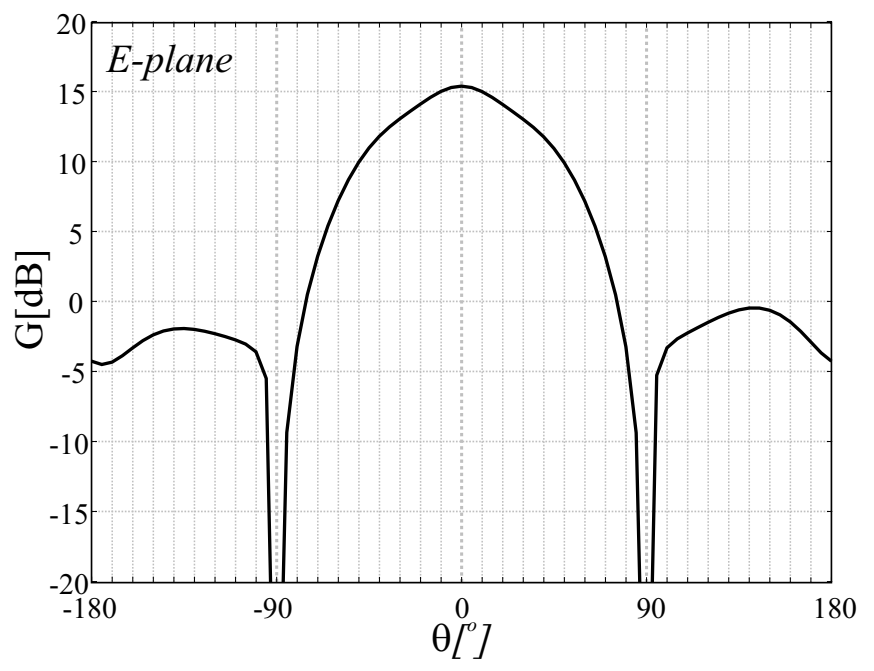

Fig. 10. Co-polar radiation pattern in the E-plane.

After the input impedance, the co-polarized radiation patterns at the central frequency of $11 \mathrm{GHz}$ are shown in fig. 9 . The beams are very well behaved with very little degradation as the pointing angle is scanned.

The radiation pattern in the E-plane is given in fig. 10 . The simulations have been done with an infinite substrate, but thanks to the suppression of the surface wave by the EBG, the radiation from the edges of the slab does not heavily influence the pattern as shown in [1].

\section{Conclusion}

An array design has been presented that clearly show the potentials of PCS-EBG to enhance the performances of one dimensional scanning arrays realized with very low cost and low profile integrated technology. The main result of this investigation is that the bandwidth over which a single layer and completely planar array can be scanned until $45^{\circ}$ without losses of efficiencies is extended to about $15 \%$. Simulation results have been presented, but the prototype is being manufactured, and considering the reliability of the simulations shown in the first prototype [1], we expect to achieve the same simulated results. Prior to the introduction of Planar Circularly Symmetric Electromagnetic Band Gap technology extreme losses arising from the radiation into the feeding half space or from the excitation of surface waves in the dielectric would render the maximum useful bandwidth achievable with comparable technology $4 \%$. This work was performed in cooperation with Thales Netherlands B.V. under the ESTEC contract No. 17539/03/NL/JA from the European Space Agency.

\section{REFERENCES}

[1] N. LLombart, A. Neto, G. Gerini and P.J. de Maagt "Bandwidth, Efficiency and Directivity Enhancement of Printed Antenna Performance Using Planar Circularly Symmetric EBGs" in Proceeding of the European Microwave Week, Paris, 3-7 October 2005.

[2] P. de Maagt, R. Gonzalo, Y.C. Vardaxoglou and J.M. Baracco, "Electromagnetic bandgap antennas and components for microwave and (Sub)millimeter wave applications" in IEEE Transactions on Antennas and Propagation, vol. 51, no. 10, pp. 2667-2677, October 2003.

[3] D. Sievenpiper, L. Zhang, R.F. Broas, N.G. Alexopolous and E. Yablonovitch, "High-impedance Electromagnetic Surfaces with a Forbidded Frequency Band", in IEEE Transactions on Microwave Theory and Techniques, vol. 47, no. 11, pp. 2059-2074, November 1999.

[4] L.L. Shafai, W.A. Chamma, M. Brakat, P.C. Strickland, G. Seguin; "Dual-Band Dual-Polarized Perforated Microstrip Antennas for SAR Applications." IEEE Transactions on Antennas and Propagation, Vol. 48, no. 1, pp. 58-66, January 2000.

[5] J. Granholm, K. Woelders; "Dual Polarization Stacked Microstrip Patch Antenna Array With Very Low Cross Polarization." IEEE Transactions on Antennas and Propagation, Vol. 49, no. 10, pp. 1393-1402, October 2001.

[6] R.B. Waterhouse, "Design and Scan Performances of Large, Probe-Fed Stacked Microstrip Patch Arrays", IEEE Transactions on Antennas and Propagation, Vol. 50, no. 6, pp. 893-895, June 2002.

[7] R. Pokuls, J. Uher, D. M. Pozar, "Dual-Frequency and Dual-Polarization Microstrip Antennas for SAR Applications", IEEE Transactions on Antennas and Propagation, Vol. 46, no. 9, pp. 1289-1296, September 1998. 